\title{
ESTUDIOS
}

\section{Roberto Falabella: un músico y ser humano excepcional}

\author{
Roberto Falabella: an Exceptional Musician \\ and Human Being
}

\author{
por \\ Delia R. Cassaretto ${ }^{1}$ \\ endoremiofa@hotmail.com
}

\begin{abstract}
"No he pensado este trabajo como información para musicólogos, aspiro a que su contenido llegue a los músicos, al ser humano, y deseo especialmente que su contenido sostenga a la juventud que lucha en este difícil arte de la creación musical. Quisiera que la lección que nos dio Roberto Falabella contrastara con ese ánimo simplista de tantos compositores del mundo entero, frente al problema de la creación a la que con frecuencia le suponen más dificultades de las que realmente debieran, pidiendo más ayuda de la que más tarde demuestran merecer"².
\end{abstract}

\begin{abstract}
Algo se ha escrito -especialmente en la Revista Musical Chilena- sobre Roberto Falabella como compositor, pero muy poco -o nada- sobre Roberto Falabella Correa como hombre, como ser humano. Este trabajo pretende -aunque sea en parte- llenar ese vacío, acercándose al creador desde ese ámbito que, en alguna medida, no menor, puede explicar su posición como artista en la sociedad en que le tocó vivir y, por lo tanto, comprender el sentido de su producción como músico.

Palabras clave: Roberto Falabella, compositores chilenos, vida musical chilena, institucionalidad musical chilena, s. XX, Gustavo Becerra-Schmidt.

Most of the articles on Roberto Falabella, particularly those published in the Revista Musical Chilena, deal mainly with his activity as composer. However, practically nothing has been written on him as a person and a human being. This article attempts to fill this gap, at least in part, focusing on his personal and human features. Hopefully it will contribute to the understanding of his position in society as artist during his lifetime as well as to the understanding of the significance of his musical production.
\end{abstract}

Key words Roberto Falabella, Chilean composers, Chilean musical life, Chilean music institutions, $20^{\text {th }}$ century, Gustavo Becerra-Schmidt.

${ }^{1}$ La $R M C h$ ha querido conmemorar los cincuenta años del fallecimiento del compositor nacional Roberto Falabella, publicando la colaboración que hizo llegar la escritora Delia Cassaretto. Ella vivió durante varios años con la familia del músico luego de su muerte: su viuda Olga Díaz Blanc, a quien cuidó en su ancianidad, y sus dos hijas, Ximena y Florencia, con las que mantiene vínculos de amistad.

${ }^{2}$ Becerra 1965: 28. 
Mucho ha que conocí de Roberto los bemoles de su vida. He ido celosamente guardando las narraciones de su historia, repetidas por los recuerdos de Olga, su compañera, la madre de sus dos hijas y su cuidadora abnegada, admiradora de su talento, de su dulzura y cómplice de sus aguerridas "inmiscuciones" en el mundo de la política. En períodos de persecución por profesar una ideología política distinta al gobierno del presidente Gabriel González Videla, Roberto estableció su domicilio de calle Lyon, lugar en que bajo su chapa de "el alemán”, se escribirán colaboraciones para el clandestino diario El Siglo.

Amigo de Neruda, de Violeta; admirador de la obra de García Lorca; amante de un vasto universo acorde a sus inquietudes intelectuales; amigo con Armando Cassígoli, Eliana Navarro, Oscar Stuardo, Efraín Barquero, Poli Délano, Nino Colli, Fernando García, Nissim Sharim.

Es quien se escribió con Shostakovich, concertando un encuentro en Rusia. En el viaje aprovecharía de ver alternativas en relación a su salud. El encuentro quedó abortado por “causa de muerte”. En su sensibilidad es un soñador comprometido de convicciones profundas y luchador infatigable. La desventura humana del diario vivir es su motivación en la lucha política, llegando a convertirse en un "panfletario": llevado en su silla de ruedas, cargaba sobre sus piernas los ejemplares del diario El Siglo y panfletos, que redactados en reuniones del Partido, debían llegar a destino. Para ocultar y prevenir persecuciones, Roberto ideó entonces encubrir las actividades políticas que se llevaban a efecto en su domicilio, bajo la supuesta existencia de un falso "club deportivo", del cual era su presidente. La idea fue, según sus contemporáneos, "simple y fantástica" y de suma eficacia: nunca se le descubrió.

Es profundamente humano en el concepto nietzscheano; amigable, aunque solitario en su dolor; creador prolífico y vanguardista en el estilo; un celoso constructor en el uso de la técnica.

La vanguardia musical de los 60 cuenta con él como constructor señero de una nueva propuesta musical, en un movimiento emergente. Este hombre se adelanta en muchas décadas a su época y genera importantes aportes a la música. Por su prolífica obra (61 composiciones en 8 años) se le ha llamado "el Mozart chileno".

Conocedor de soledades, padre amante, amigo incondicional, compañero político, hijo triste de madre permanentemente ausente; cuidado por afectos femeninos que había en su entorno, y económicamente bajo la tutela de su progenitor. En lo artístico brilló con luz propia y es señero en los caminos de los jóvenes músicos que ven en él al gran hombre, admirado, respetado y aún desconocido en su aspecto humano.

Lo conocido de su biografía se remite fundamentalmente a su obra. No hay referencias de él como el ser humano que debió sobrellevar penosas limitantes en diversas facetas: de salud, afectivas, del alma, económicas y las ausencias que agigantaban su dolor metafísico. Tenemos en la vida de Roberto una oscuridad profunda, que él reconvierte en luz a través de su obra. La creación es un desgarro y es, en su breve existencia, un prolífico creador, dejando con su obra testimonio de la transformación de una dolorosa vida en belleza, cuando se suma a ella su talento. Ningún dolor es estéril en su sensible vida. 
Roberto nació el día 13 de febrero del año 1926, su abuela materna asistió el parto en su casa. Su padre es Roberto Falabella Finizzio y la madre Marta Correa Escobar, quien sólo tenía 15 años al nacer su hijo. Le sobreviven: su hermana, sus hijas Ximena y Florencia, las que no tienen descendencia; sus sobrinas Silvia y Marcela, las hijas de su tía Eliana Falabella; las señoras Liliana, María Luisa y Teresa Solari Falabella, las cuales constituyen hoy el importante soporte económico de las hijas, quienes viven austeramente.

Roberto tuvo una familia que trascendió las formas de lo convencional. Curioso resulta saber que no siendo civilmente reconocido por sus progenitores, su madre le "dio" más hermanas, pero adoptivas. La misma madre que no acompañó con su presencia a los que nacieron de sí. Atípica y dolorosa verdad en la vida del músico: una madre ausente, que prodigaba "maternidades nuevas".

Su primera etapa de vida fue al cuidado de su abuela materna y de su tía Hilda. Roberto veía muy poco a su madre. Ello era motivo de ácidos comentarios de terceros, y las constantes ausencias hacían de sus encuentros una experiencia que transformaba el ambiente y estado anímico del músico, constituyéndose cada visita en un acto para recordar profundamente. Las esporádicas visitas podían lo mismo sumir a Roberto en una profunda depresión o en un grato estado de ánimo.

Nació con el síndrome de Little, que es un trastorno extraño que ataca a los niños en los primeros años de vida, causando músculos espásticos y rígidos en las piernas y, en menor grado, en los brazos, dificultando el asir objetos, gatear y caminar. A diferencia de la mayoría de las otras enfermedades que afectan al cerebro, esta enfermedad no empeoraba a medida que los niños crecían, sus incapacidades permanecían relativamente igual. Aun cuando la parálisis cerebral afecta el movimiento muscular, no está causada por problemas en los músculos o los nervios, sino por anormalidades en el cerebro que interrumpen la capacidad de éste de controlar el movimiento y la postura. Más tarde se le definió como un cuadrapléjico severo (parálisis total). No podía realizar movimientos voluntarios, hablaba con dificultad, su fonética era deficiente, aun con ello, le era suficiente para comunicarse. En ocasiones, cuando se sentía ofuscado, lograba alzar su voz para decir con energía cuanto pensaba necesario explicar o reclamar. Fundamental en ello era la presencia de Olga o de "tía Hilda". Luego esa tarea fue propia de sus secretarios, Eduardo Moubarak y Raúl Rivera. Ellos debían atender rigurosamente las indicaciones de él, para traspasar a la partitura la música que brotaba en su mente.

El intenso tiempo compartido con Moubarak fortalece una amistad que trasciende al concepto de "trabajo", ya que Roberto no "pagaba" esos servicios de asistencia en sus dictados musicales, eso era propio de Carlos Vasallo, albacea de Roberto.

Según el propio decir del artista, pocas veces realizaba cambios en su obra, porque si había algo que no le sonara bien en su mente, no lo pasaba a la partitura.

Su enfermedad le jugaba muy malos momentos. Había circunstancias en que no le era dable realizar su estricta rutina de estudios y ello le dificultaba el avance que tenía programado, lo cual le causaba estados de molestias y enojos -nada 
ligeros- consigo. Era un hombre disciplinado en sus actividades intelectuales, solía organizar con mucho rigor sus horarios, ello fue una determinante para su espacio en la vida familiar. Compartir su tiempo con las hijas era lo más importante fuera de la música.

Remitiéndonos a las características de su enfermedad, estamos ante un hombre que jamás pudo erguirse sobre sus piernas, no podía abrazar, no podía afeitar su rostro ni ejecutar los ineludibles actos de natura, lo que significaba que había ocasiones en que hasta la incontinencia era su verdugo.

Olga declaró: "Tenía que cultivar la paciencia. Estar en la silla de ruedas que su padre le compró, era para él una incomodidad, puesto que se deslizaba por sus espásticos movimientos, sin poder continuar sus lecturas”.

Salía en silla, llevado por Olga, a pasear con las niñitas, cargando con indisimulado orgullo su mayor tesoro: las tres mujeres de su vida.

Tempranamente, Roberto acusó los síntomas de su enfermedad. Siendo un niño extremadamente dulce en sus rasgos y expresión, agudo en la observación, creció en un entorno cultural no acorde a la manifestación del desarrollo de su talento y muy precario en estímulos para su crecimiento intelectual. Aprendió a leer por sí mismo, siendo un niño muy pequeño. Luego continuará generando sorpresas por su brillante coeficiente intelectual e ilimitada agudeza mental. Transcurría el tiempo y el pequeño Roberto no caminaba, no se le proporcionaban estudios formales y carecía de perspectivas, dada la limitada visión de futuro de sus cuidadoras, la abuela y las tías, para quienes los signos de la enfermedad eran algo más cercano al popular concepto de lo que sería un niño "tontito". Ante ello, reaccionaban otorgándole ternura, en sustitución de la ausencia de la madre y sus cuidados. El niño se desarrolló emocionalmente con fantasmas afectivos por la poca relación entre sus progenitores. A petición propia se busca cómo cursar sus estudios formales.

La vida de Roberto y su hermana transcurre, en los primeros años, domiciliados en calle San Pablo № 1117, Santiago de Chile, lugar que era arrendado por su padre, siendo atendidos por los mencionados familiares, a quienes denominaba "la chusma".

En el pasar del tiempo, instalados con el padre desde los nueve años, la esquematización de su vida repetirá ciertos cánones que son consecuencias de su irregularidad civil. Los hermanos Falabella Correa civilmente no estaban documentados, razón por la cual al nacer Ximena y Florencia se reiteró la condición de "N N", lejos de toda voluntad del artista, pudiendo ordenar ello el 13 de noviembre de 1954, cuando por fin se casa civilmente con Olga.

\section{PRIMEROS ESTUDIOS}

Ante la imposibilidad de cursar estudios de manera regular, tuvo profesores particulares que formalizaron su aprendizaje ante la entidad educacional, siendo aprobado en ellos con un excelente rendimiento, lo que, por cierto, aumentó el orgullo paterno ante la incipiente brillantez intelectual de su hijo. Su primera maestra fue la Sra. Berta Platoni, que consolidó la formación que le orientó a descubrir su vocación humanista. El orgullo paterno contrastaba con el severo pudor que le 
causaba su enfermedad, razón por la cual construyó una casa en el balneario de Las Cruces, para que el joven hijo pasara los veranos, alejándole de la mirada de los curiosos.

En su período de púber, las cuidadoras prontamente se sentían incapaces de hacerlo. La sensibilidad de este joven, que tenía el privilegio de "elegir", optó por quien le pareció la mejor y escogió a Olga, quien, diez años mayor que él, fue, a contar de entonces, la que le prodigó toda suerte de cuidados hasta el último de sus días. Hizo de ella una madre -la propia y la de sus hijas-, una cómplice, una secretaria, la confidente, la que sin indicarlo él sería la intuitiva celadora de su obra, guardándola para testimoniar su creación.

\section{MARTA SU MADRE Y LA AUSENCIA}

Estudios previos de la vida del artista señalan a Marta como la madre prototipo. La realidad es distinta, no fue la omnipresente ni la que se entregaba de tiempo completo a las duras labores de cuidar a un hijo con semejante limitación física. De ahí la razón de la constante presencia de Hilda en la vida del músico. También cabe señalar que Roberto tenía una gran relación afectiva con la que sí era la esposa de su padre, doña Paulina Peragallo. Marta tenía prolongadas ausencias; las razones le pertenecen, pero con ello no permite imaginar la maternal abnegación que investigadores anteriores indican. La ausencia fue razón de incomunicación, es más, tal vez fue el peculiar modo de encuentros, el nexo que fortaleció la mutua admiración y respeto, ya que otorgaba la posibilidad de observarse dentro de cánones de objetividad, sin la distorsión afectiva que da la continuidad de una relación convencionalmente normal.

Roberto era gran conocedor de las cualidades y defectos de su madre; no eran sus "faltas" motivo de no ser merecedora de su respeto y cariño. Quizás sí en Marta había una natural pérdida de objetividad al respecto, lo que le llevaba a no obviar las "poco amables" reacciones de Roberto, quien, dentro de sus enormes bondades, parecía a veces ser "otro" por la ofuscación que le causaba el agotamiento de su parálisis. En circunstancias como esas, la madre no lograba cumplir el objetivo de la visita y se retiraba rápidamente. Esta era una actitud incomprensible para el padre del músico y le causaba profundas molestias, pidiendo que no fuera más si sus visitas habían de ser devastadoras. A Roberto se le pasaba su manifestación de enojo más pronto que el pesar de sentir que había sido ingrato frente a su entorno. Luego de alguna circunstancia como esa y gracias a su inconmensurable sensibilidad, generó posibilidades de encontrarse de manera semiclandestina con su madre, desacatando la determinación de su padre, que tiene ciertos reparos en admitirla al interior del hogar. En alguna ocasión el músico preparó una salida no acordada para visitar a su madre, haciendo cómplice de ello al chofer de su padre y a su cuidadora, la que quedó a merced del enojo de su progenitor.

No es clara la situación de conflicto generado entre los padres del artista, sí es sabida la enorme diferencia de edad entre ambos -ella 15 años, él 37- y la muy diferente posición socioeconómica, en verdad, extrema. Marta era la hija de la costurera que trabajaba en la sastrería y tal vez ello concitó discrepancias insalvables. A excepción de los hijos, no había más que los uniera. Marta era una mujer de 
peculiar encanto y, conocedora de su atractivo, compartía con su hijo misceláneas de sus viajes. Así es como van integrando una relación que pasó a ser importante para sus inclinaciones académicas: los obsequios traídos de sus viajes son en su mayoría libros y, por cierto, música.

Falabella Finizzio quería ante todo el bienestar de sus hijos y es así como la situación se subsana, pero las lejanías de las visitas de su madre se han de repetir con sus viajes. El desencanto de la espera ya no da aires de belleza a la ausencia y el artista se sumerge en profundas depresiones. Cuando enfermaba se hacía necesario procurar la presencia de Marta y ella solía no estar ubicable. Era en aquellas ocasiones cuando Roberto la justificaba. Sufría, a la par de su cuerpo, la prolongada falta. Entraba en esos estados depresivos de los cuales Olga procuraba trabajosamente animarle, alentando en él la continuidad de sus horarios para estudiar y componer, que ella aseguraba cumpliendo las pesadas tareas que esto implicaba. Olga recordaba: "Siempre tenía que levantar a Roberto, no sólo por su invalidez, sino porque su desánimo era mayúsculo, en ocasiones. Lo más delicado era hallar el modo de sustraerlo de sus depresiones. Roberto lloraba en las noches y procuraba que nadie se enterara, solía reír con sus amigos, siempre se le podía ver con una sonrisa amplia. No dejaba mostrar sus reales estados de ánimo”.

Se comenzó a deteriorar su salud y debió ser intervenido quirúrgicamente en repetidas ocasiones y, por cierto, sin más figura materna, por adaptación, que la de Olga, y las visitas de la tía Hilda y Carlos, su hermana María Gabriela, sus amigos y obviamente la presencia del padre, para quien ni todas las obligaciones de la vida le impedirían acompañar "a su niño".

\section{SU ABUELA, PURA ESCOBAR}

El día que Roberto nació, su abuela materna señaló a Olga que "el niño era 'sanito' y robusto, a la par de 'precioso’. ¡Cómo íbamos a suponer que venía enfermo!”. Fue una abuela que, conmovida por la enfermedad de su nieto, intentó prodigarle toda la ternura que era capaz de sentir, y aportó cuidados "metafísicos", consistentes en ubicar medallitas entre las ropas del niño para recibir protección, oración mediante de su parte, con la ilusión incumplida que "algún día, Robertito, sanará”.

\section{TÍA HILDA}

Tía Hilda no engendró hijos, dedicó su tiempo a la labor de cuidar a su amado sobrino y dispensarlo del obligado encierro. Le acompañó y cuidó por toda su vida, y su marido, profundo admirador del artista, reía diciendo que tamaño ser humano debiera ser llamado "Robertazo", observación acertada de quien fue compañero intelectual de tertulias. Amenas reuniones fueron vividas en este trato tan admirado que tuvo de su tío político, con quien compartía la contingencia nacional y sensibles temas, inherentes fundamentalmente al cuestionamiento de los ejercicios doctrinales, de credos e ideologías, de deportes y utopías; de la vida. Cuando ocurre la muerte de su sobrino, Hilda cae sumida en una depresión gravísima. No se recuperó jamás de semejante duelo, haciendo de su espacio una 
sala de recuerdos, donde instaló los diversos objetos que le quedaron de la infancia de Roberto.

\section{SUS MAESTROS}

Sus primeras lecciones para cursar formalmente sus estudios primarios estuvieron dirigidas por la Sra. Platoni. Una maestra anterior declaró al padre que era inviable enseñar al joven: "Nada se puede hacer al respecto, excepto acompañarlo a hacer juegos donde tenga la ocasión de interactuar con amigos de su edad, pero 'nada' se le puede instruir en lo académico, porque el joven no es intelectualmente sano". La razón de esta opinión fue la incapacidad para atender la fonética enferma de Roberto, y el descontrol de sus movimientos, lo que causaba incomodidad y perturbación a dicha maestra. Este tropiezo no destruyó la tenacidad de su propósito y fue insistente en pedir que se le buscase una profesora “capaz”. Finalmente, aprobó la formalidad académica de educación de humanidades, obteniendo calificaciones de excelencia.

Vino entonces la etapa en que comunicó a su padre la intención de realizar estudios superiores; cuenta ya con dieciocho años. Su padre, aún con la disposición de complacerlo, no entendía cómo, con las limitantes físicas de su hijo, podría éste realizar su proceso de aprendizaje. Se cuestionaba: “CCómo habría de hacer para conseguir sonido de algún instrumento? ¿Cómo aprendería la técnica? ¿Qué requería para la ejecución de su proyecto, cómo canalizarlo? La necesidad de Roberto era imperiosa, quería aprender música. Ello habría de ser su mayor sentido de comunicación. Nuevamente hubo quienes sostuvieron que nadie era capaz de enseñar música a Roberto, pero apareció alguien "capaz", fue Lucila Césped, maestra de teoría musical. Estamos en los años 1945 y 1946, la maestra, con dulzura e ingenio, ha de hallar la forma de enseñar teoría y solfeo al inválido estudiante. Dentro de las limitantes naturales del músico, la maestra Céspedes desarrolló, a la par de su talentoso alumno, nuevas técnicas en el ejercicio de su método, enseñándole en sus clases de teoría musical a "obtener notas y sonidos" haciendo soplar a Roberto una peineta acompañada de un papel... y consiguió sonidos... “¡Oh, qué bien sé tocar!”, rió el músico con su maestra, haciendo alusión a cierta fábula.

Otra de sus maestras fue la Sra. Julia López, en el año 1947. En los dos años siguientes, 1948 y 1949, la musicóloga María Ester Grebe le enseñó la asociación sonido-grafía y graduación interválica. Además, cuenta con un maestro de gran talla, como lo es Alfonso Letelier, con quien en los años 1949 y 1950 ha de completar sus estudios de armonía. Su hijo, Miguel Letelier, reciente Premio Nacional de Arte, mención Música 2008, declara que, al decir de su padre, Roberto era dueño de un talento extraordinario, y su obra debiera estar más presente, ya que es una de las que marcó una alta calidad en Chile, a pesar de la corta vida de su autor y las limitantes físicas que sobrellevó.

Gustavo Becerra, prominente músico, antes de ser Premio Nacional, fue su maestro de composición musical. Con él, no sólo generó una relación discípulomaestro, además, fueron íntimos amigos, tanto, que recibió de su viuda, en prenda de recuerdo, el reloj del artista. El maestro holandés Fré Focke, en tiempos ya 
posteriores, al comienzo de las creaciones de Roberto, en el año 1954, también impartirá sus conocimientos al músico nacional.

Los impedimentos físicos de este alumno eran una dura barrera. Esta fue salvada al cabo de algunos años de estudio gracias, principalmente, a su particular talento. El músico inició entonces su prolífica obra creadora, desgraciadamente demasiado breve, que fue reconocida y aplaudida por todos.

Se ha compilado su obra a través de quienes, conocedores de Falabella, se dieron como tarea "buscar" los legados de su música, dando así con el hogar de la viuda y sus hijas. Aquélla, sabedora e intuitivamente, guardó con celo y amor la presencia inmanente del compañero de su vida, del artista, que ha ido ocupando el sitial que le corresponde en las artes nacionales, aún sin haber recibido jamás el Premio Nacional de Arte, probablemente por su juventud.

La divulgación de su música trasciende fronteras. El director de orquesta Eduardo Moubarak, declara: "Si Roberto hubiese vivido 30 años más, hubiese sido el mejor compositor del siglo XX en Chile. Era el de más inventiva, era el más novedoso de todos, de un ingenio que se ve poco".

Por otra parte, Sergio Ortega y el mismo maestro Becerra han admirado y promovido también su obra. A la poca difusión lograda por la música de autores chilenos en el ámbito local, tema observado, expuesto y criticado por el mismo Falabella ${ }^{3}$, se agregó en su caso, durante la dictadura militar, su reconocida ideología política, razón por la que se intentó evitar la ejecución de su obra en el Teatro Municipal en 1988. Ante tal situación, el director italiano Roberto Abbado declaró que la radical importancia de su obra trascendía las ideologías y que la envergadura del dominio de la técnica, lo vanguardista y el contenido de la obra en sí, son mérito suficiente para ser ejecutada.

\section{EL HOMBRE}

Se va tejiendo en esa permanencia de los cuidados que dio Olga a Roberto una historia de singularidades que cuando llega él a cumplir los veinticinco años le dará la alegría inmensa de ser padre, al nacer, en enero de 1951, Ximena. Compartieron todo, vicisitudes y esperanzas. Ella, la compañera imprescindible de sus días, prontamente le dio una segunda hija, cuando en noviembre de 1952 nació Florencia. Ya tenía casi 27 años y la felicidad en él es extrema: es padre de dos niñas. Recibe entonces, entre alegrías compartidas y verdaderos actos de elevación para el hombre-artista, diversas bromas de sus amigos, ya que por la turbación emocional de los hechos es difícil para él verbalizar. Refiere a su amigo Gustavo Becerra, bajo una emoción absoluta, que tiene una "jija”. Esto pasó a constituirse en una broma reiterada de los amigos. Divertido explicaba que lo que él decía era: "que tenía una jija” y ante su segunda hija, refirió que tenía otra "muñequita". En cierto modo así era, dada la escasa edad de la mayor, que se asomaba a la cuna para jugar con su hermanita. Nuevamente convertido en presa de su sobreexcitación emocional, Roberto aludía así a su segunda hija, que tenía unas pocas semanas. Guardó la noticia para ser dicha por sí mismo al regre-

\footnotetext{
${ }^{3}$ Falabella 1958a; Falabella 1958b.
} 
so de su hermana y su madre. Su padre, que murió el 19 abril del año 1951, jamás se enteró que había sido abuelo.

Olga le había dado cuanto podía esperar: comprensión, cuidados, abnegación, su peculiar ternura, fundamentalmente, y sus hijas. Estas habrían de vivir disonancias existenciales de profunda gravedad, pues Roberto, con su temprana muerte, minó en la vida emocional de sus hijas los rasgos de una niñez normal. La pérdida de la situación económica completa el caos. Cabe preguntar ¿qué sucedió si el músico era hijo de un acaudalado burgués? Se dan distintas versiones respecto a su salud, la más silenciada es que murió con una perturbación mental, razón por la cual es precisamente no divulgada, conjuntamente con sufrir el mal de Parkinson. Me refirió esta información Olga. Ella es a mi ver extraordinaria, concepto compartido con el maestro Gustavo Becerra, quien señala que la vida de Olga junto a Roberto fue "excepcional, llena de afecto, admiración y eficiencia" 4 .

La muerte de su padre trajo consigo muy negras consecuencias para la estabilidad económica de la familia. Situación poco clara, dado el hecho de que el padre fue sistemático y generoso proveedor. ¿Qué ha sucedido entonces? Olga fue un moderador natural de los gastos excesivos en que incurría Roberto frente a situaciones de terceros involucrados, que buscaban inescrupulosamente "sacar partido al burgués artista”, como escamotearle, por ejemplo, colecciones de libros y objetos diversos. Hay hacia Roberto una mirada extraña, que lo sitúa al mismo nivel de burgués que su padre, no siendo más que participante de esos bienes que le hace disfrutar. Es víctima de inescrupulosos actos, los que ha de "excusar" por la necesidad de quién o quiénes los hayan realizado. Aunque la pérdida de sus libros lo alteraba, prefería no ver mala intención. Él -decía Olga- era demasiado crédulo, fue víctima de muchos compañeros del partido que tanto defendía.

Ante las dificultosas condiciones económicas tras la muerte de su padre, Roberto debió encontrar el modo de proveer el sustento familiar y resuelve hacer clases. Sergio Ortega fue uno de sus discípulos, al igual que Hugo Pavicic. Tras las enseñanzas, que traspasaron lo puramente musical de un maestro, recibieron lecciones integrales y tuvieron el privilegio de conocer al artista, a la persona, y no sabían que apuntalaban al hombre en su más insólita soledad y complicada existencia. Fueron eslabones en la cadena creativa de la vida de un artista que humanamente sufría su condena de ser frágil.

Roberto tenía ciertas restricciones para acceder a regularizar civilmente su vida, y bajo razones de índole nunca esclarecidas, no fue reconocido civilmente por la madre, acreditándose ello sólo por la partida de nacimiento. Su reconocimiento paterno con asidero civil-judicial se remite a un párrafo en su testamento en donde señala: "Reconozco como mi hijo natural a Roberto Falabella Correa". En otra parte dice: "Instituyo herederos de su legítimo a mis hijos María Gabriela y Roberto Falabella, por partes iguales”. Me pregunto ¿qué ha sucedido con el designio de equidad, bondad, protección y amor que tuvo el padre para con sus hijos? ¿Qué le han hecho a Roberto? ¿Roberto fue engañado? Ello es parcialmen-

${ }^{4}$ Extraído de la correspondencia entre Gustavo Becerra y Florencia, la hija menor de Roberto. 
te así. Existe un testamento en que se aclara que ha de recibir la mitad de sus bienes y la otra su hermana. ¡Y él jamás lo supo! Murió creyendo haber sido desheredado de su padre, no lo cuestionó, no averiguó o ¿se desentendió?

Durante los años que Roberto sobrevivió a su padre se las arregló para continuar solventando sus gastos. Aún había albacea, un tutor; pero al morir todo empeorará más allá de lo ya complejo que fue vivir sin su padre, a quien el artista, por cierto, respetaba profundamente. Hubo exorbitantes gastos por sus cirugías; aún con ello, la herencia cubría y debía bastar para él y las venideras generaciones. Sin embargo, la sustentación económica decreció con mucha celeridad, llegando la familia a una indefensión no imaginada. Olga realizó diversos oficios que generaban el sustento. Aún así la realidad se revistió de una precariedad que en ocasiones era en extremo penosa. Hay algunos "tesoros" de los que debió deshacerse; la extrema urgencia del cuidado de sus pequeñas hijas le lleva a ir transando ciertos bienes familiares, entre ellos, un libro dedicado a su amigo Roberto, por el poeta Pablo Neruda. Parte de su biblioteca fue desmembrándose, como una repetición de la lenta agonía de su compañero ausente. No todo es "convertible en dinero". Olga sabe muy bien que hay en su poder un tesoro mayor, el legado de la obra de su compañero. ¡Cuánto tiempo guardó con celo las partituras! Hasta los cuadernos de estudio del músico, que fueron compilados y ordenados por sus inmediatos y amigos, los donó para material de consulta de los estudiantes de la Facultad de Ciencias y Artes Musicales de la Universidad de Chile. Todos estos materiales sirvieron para el riguroso trabajo que realizó el Doctor Luis Merino Montero ${ }^{5}$.

Falabella Finizzio no alcanzó a saber de los logros de Roberto, como a su vez éste desconoció los hechos de su padre, tales como la creación de becas para los alumnos pobres de la colonia italiana y sus actividades como benefactor de la Scuola Italiana en Chile. Siempre reconoció los leales servicios de sus empleados, por tanto no hubiera permitido que sus nietas estuviesen en el desamparo económico que les tocó vivir. El padre de Roberto tenía la talla perfecta de un buen ser humano, convencional y ecuánime, afectuoso y justo, pragmático y correcto. Las interrogantes continúan siendo: ¿qué sucedió con los bienes que legó a su hijo?, ¿le robaron?, ¿por qué ese detalle de ser heredero no le fue informado al músico, al menos a través de la hermana?, ¿fue engañada ella también?

Olga, junto a sus hijas, vivió pobremente. María Gabriela tuvo un buen pasar, su estándar de vida no varió con la muerte del padre. Roberto pasó estrecheces económicas y Marta tuvo una mala relación con su nuera y nietas, las que fueron "desarraigadas", llegando a vivir a Puente Alto. Olga era sindicada por Marta como dilapidadora de la fortuna de su hijo, olvidando que su esposo era albacea del artista. No hay una explicación o argumento que dé a entender el destino de esa fortuna. Al quedar Roberto sin herencia, su hermana compartió con él una parte de la suya.

\footnotetext{
${ }^{5}$ Merino 1973.
} 


\section{OLGA, SU COMPAÑERA}

En anteriores notas biográficas de Falabella se cita a Olga como "la enfermera". No lo era por formación, sí tenía vocación y aptitudes para ello, sumado a un gran sentido de responsabilidad y abnegación. Era de carácter adusto, formas severas y recta, respetuosa y con gran facilidad para aprender cuanto se le enseñara. Roberto le indicó cómo transcribir música a las partituras y ella lo aprendió muy eficientemente. Ambos se fueron adaptando. Generaron un conocimiento tan intuitivo el uno con la otra, que la relación fue simbiótica, tanto así, que cuando en 1949 Olga viajó a Temuco, se le buscó con desespero, se le pidió que regresara a cuidar a Roberto. Estaba conflictuada; y sabía que él no estaba bien atendido. Fue buscada con empecinado tesón porque "el niño" decaía en su ánimo. Luego, con su regreso, la complicidad va creciendo entre ambos. Hay cambios vertiginosos en el tenor de su conocimiento y un mirarse distinto. Dos años más tarde nace Ximena y casi dos más, nace la hija menor. Su vida comienza a reordenarse y algunos aspectos pospuestos traerán malhadadas consecuencias.

El músico está en plena etapa de crecimiento, su aprendizaje y natural talento han iniciado la ruta de la creación. Su vida en pareja con Olga recibe objeciones de Marta, de la cual suponía comprensión; en cambio, su padre no "obedeció" las sugerencias de su medio social. La palabra amor, en Olga, adquiría una connotación mayor cuando era sustituida por "admiración”, al referirse al artista.

\section{SUS HIJAS}

Las hijas, expuestas a la pérdida "social" temprana, a la incomprensión de la muerte del padre y al despojo económico que les victimizó, inician una vida de calvario. La menor pasaba constantemente enferma. La madre, atenta al deterioro de la salud emocional de sus hijas, busca mantenerse el mayor tiempo posible cerca de ellas, como lo pidió Roberto antes de su muerte: "Olga, que nunca le falte nada a las niñitas”. Así expiró, pidiendo por sus hijas, que complementaron el sentido de su vida para vencer tantos obstáculos. De cuánto les faltó a ellas y a su viuda no fue falta de capacidad, ni tesón, fue el peso de las puertas cerradas ante la fragilidad.

La mayor pasó su período laboral como administrativo en el Ministerio de Educación y luego trabajó largamente como secretaria en un matadero. La menor, en tanto, cursó su magistratura en filosofía en la Universidad de Chile y ejerció largamente la docencia. Publicó, con recursos propios, un libro de filosofía como material educativo de la enseñanza media, con reconocimiento ministerial. Y su mala salud no le permitió concluir el doctorado.

El hijo del burgués, soñador de ese mundo equitativo, no imaginó tanta desventura, ni aun cuando compone la música a esos versos que aluden al "día tan largo" Quizás los pesares de su familia fueron la metáfora de dolor como se duelen los poetas, los sensibles de los dioses. La vida le cobró dos veces su talento. El primer canje fue su cuadraplejia por su inteligencia y, el otro, la miseria de los suyos.

\footnotetext{
${ }^{6}$ En 1957 el compositor escribió Dos poemas, para barítono y viola, con textos de León Felipe; el segundo de los poemas empleados se tituló "Que día tan largo", al igual que la segunda canción.
} 


\section{VIOLETA PARRA Y PABLO NERUDA}

En la refulgencia del genio creador no podían dejar de conocerse Violeta Parra, Pablo Neruda y Roberto Falabella, portentos de nuestra cultura nacional. Fueron amigos más allá de lo ideológico, se aunaron en las artes y en el desgarro de la creación, cada quien en su expresión otorgó al otro el goce estético de compartir. Roberto a ellos, con su ejemplo por las ansias de vivir y vivir con alegría por la lucha de una causa de igualdad, por la belleza del arte, por la alegría de pensar para sentir cabalmente la vibración armónica de los sones de la vida, diversos sones, todos los sones del pensamiento aunados en un solo gran son, como el que sugiere filosóficamente el concepto ideológico de Marx, que es encarnado por Roberto, quien, en su trayectoria de pobre a burgués, desarrolla el encuentro con lo metafísico, dándose de lleno a la creación y al mensaje desde la dialéctica materialista que Marx propone para concluir en las Artes.

Iba Violeta con toda animosidad a cantarle a Roberto, llevaba parte de sus instrumentos y solía saludarlo de "folclórica forma", lo que le animaba. Le preguntaba qué quería "que le tocara”, y así es como quedó Violeta, interpretando Casamiento de negros, en la memoria de sus hijas. La menor se sentía un tanto intimidada con la presencia de la amiga que le cantaba al papá. Pablo compartía con él en Isla Negra, en sus días de descanso, leyendo en alguna ocasión -o varias- sus Odas para que su invitado se sintiese agasajado. Leer las Odas constituía para Pablo un momento de obsequiarse ocio, junto a Roberto. Verdaderamente, el motivo central que les convocaba era hacer un análisis de los poemas de Neruda a los cuales Roberto habría de musicalizar. Compartieron, entonces, La lámpara en la tierra y su contenido. La amistad que cultivaron Neruda y Roberto fue profunda y comprometida. En alguna de esas reuniones se les unía Marta, que al poeta gustaba tener de visita, ya que se hacían "regalar por la excelencia de su cocina”. Ese mismo amigo, que le acogió en su mundo de caracolas, lo despidió con profundo pesar en el ritual previo a su sepultación en el mausoleo familiar. Perfilando la trascendencia que éste habría de tener, en el día de su funeral lo definió en su discurso como "un joven héroe jamás vencido"7.

\section{SU HERMANA}

Puedo referir sólo a nivel anecdótico parte de la vida de su hermana con Roberto. Él se sentía con el deber de aliviar los tiempos libres de ella jugándole algunas bromas con la preclara intención de divertirla y aminorar los estados de desánimos en la ausencia materna. Así acortaban las horas hasta la llegada del papá. Por ejemplo, la operación de la muñeca de María Gabriela, muñeca que "murió", porque la intervención fracasó, como cruel parodia de la vida de lo que acontecería luego con el músico. También está la búsqueda de "tesoros" consistentes en guardar palillos de tejer de la abuelita Pura, escondiéndolos en el interior de un caballo de cartón piedra que, según las cuentas sacadas por los niños, deberían aparecer en número importante cuando ellos "abrieran” el caballo. ¡Grande fue

\footnotetext{
${ }^{7}$ Discurso de Neruda, citado en Merino 1973: 93-94.
} 
la sorpresa al descubrir que dicho tesoro no estaba ahí! La abuelita los quitaba cada día. Ambos se sintieron frustrados y avergonzados de la "derrota", haciendo pacto de no "preguntar para no evidenciarse". También lloraron por sentirse burlados, tratando de esclarecer cómo fue ejecutada la "traición del enemigo".

\section{PODER ADQUISITIVO DEL PADRE}

Los hermanos Falabella Finizzio segmentaron su herencia y el padre de Roberto, con suficiente fortuna, dedicará su tiempo a disfrutar de las óperas, a la par de sostener sus ingresos. Ello permitió que el artista pudiese tener acceso a la educación del modo que la tuvo. Él hubiera elegido estar más cerca de aquellos por los cuales luchó desde una postura ideológica progresista, desde una cosmovisión acertada y peculiar, desde un sentido ético de los conceptos equidad, educación, arte, desde una sensibilidad por comprensión y arte por vocación, desde tantos conceptos, perfectamente atendidos desde su racionalidad, espíritu y conocimiento "del hombre".

Los gastos por su mala salud significaron un continuo "egreso de las arcas", que no habían de tener rédito, al igual que los de sus estudios, que representaron un desembolso mayúsculo y que tampoco significaron un retorno económico. La verdad, de no ser por el cuantioso monto de las arcas de su padre, con toda seguridad Roberto hubiese tenido insalvables traspiés en su educación, pero felizmente la fortuna se encontraba en poder de un hombre generoso, que no minimizó recursos en favor de su hijo.

\section{ALUMNO AVANZADO}

Entre los años 1945 y 1950, realizó sus estudios y en ese último año comenzó su primera etapa de compositor. Además, escribió poesía. Siempre estaba captando el universo que le llegaba por sus hermosos ojos verdes, que quedaron como simbólica tonalidad para un mirar optimista y vencedor de dificultades. Roberto no sólo se expresa en notas y pentagramas, sus actividades incluyen filosofía, arte, literatura, ciencias, ajedrez, asistencias al cine, al fútbol; además, pautea un programa radial.

Entre su catálogo de 61 obras musicales terminadas, destacan especialmente la Sinfonía $\mathrm{N}^{\circ} 1$ y Adivinanzas para coro, las que obtuvieron primeros premios en los Festivales de Música Chilena de los años 1956 y 1958, así como Palimpsestos, para voz y grupo instrumental, con textos de Federico García Lorca, de 1954, dedicada a su hija Florencia.

\section{SALUD, AGONÍA Y MUERTE}

Su enfermedad avanza, destrozando toda posibilidad de verle caminar, de poder oírlo hablar bien, de verle jugar. Todo parece inalcanzable en la mente de los que le ven así, menos en él, que conforme va creciendo, agudo en la observación, va conteniendo y aprehendiendo cuanta información se le dé por respuesta. Su mirada vivaz es el nexo con el mundo que comienza a escrutar. Así es como, median- 
te lo que se le muestre, ha de interrogar con la mirada. A manera de recuerdo, así lo relató él a Olga, le decían: "Robertito, acá dice, 'música' y/o diversas palabras"; entonces pedía que le dijeran el abecedario y se lo mostraran. "Aprendí a leer de ese modo", refirió.

Sí, su cuerpo le perturbaba. Deseaba utilizar sus brazos para "hacer cariño", coger los libros por sí mismo; soñaba que podría. Si pudiera caminar, sería jugador de fútbol. Obviamente, un sueño muy válido para un pequeño inválido. En medio de esos sueños infantiles tiene sus primeros "asuntos quirúrgicos". Más operaciones, más sueños, él no perdía la esperanza. Hasta que llegó a conocerse con el doctor Asenjo, Premio Nacional de Ciencias, al cual explicó sus postergados anhelos. Presuponía que los resultados de la cirugía no serían óptimos. Aún así, en medio de un afán altruista, se somete a algunas operaciones, casi en carácter experimental. No fuese que por falta de un voluntario no se diera con alguna forma de mejoría a la parálisis que otros como él sufrían. Roberto también quiso ser parte activa en la búsqueda. Sus sueños fueron quedando cada vez más "aplastados en el quirófano”, pero su mente comenzaba vuelos inimaginados. Había obras por terminar, mucho que crear, estaba rebosante de inspiración, aún en medio del dolor de lo humano, de su mismo dolor.

Se sostenía con estoicismo ante ello. Lo que lo aniquilaba era la desigualdad, la falta de belleza interior en el ser humano, la discriminación, la intolerancia, el irrespeto, la ignorancia, la explotación, la inautenticidad, las complejidades de las mentiras amparadas al alero del credo cristiano, el abandono a los débiles y, entre los débiles de los animales, a los que amaba. De los caballos, decía: "¡Qué maravillosos!, ¡qué músculos tan soberbios!” Tenía un perro que dormía echado bajo sus pies y que no dejaba acercarse a nadie, incluso "disputaba sitio de territorialidad" con Olga y sus hijas; ellas lograban acercarse, pero antes les gruñía. Debían sacarlo de su lado y ello era motivo de profundo dolor. Su perro Alfil, cuando le olfateaba comenzaba a aullar. Roberto lo añoraba, debía cambiar el habitual recorrido de su paseo para no perturbar a su "desterrado amigo". Anteriormente debió sufrir la pérdida de Rasputín, del cual, comentó a Olga, consiguió el buscado "tono" de una nota que no decidía en una de sus composiciones.

El 12 de noviembre se festejó el sexto cumpleaños de su hija Florencia. Comenzando las primeras horas del 13 de noviembre, acusó sentirse mal, con un gran dolor que casi le hacía perder su sentido de conciencia; pidió que se le aplicase un enema, acción que no cumplió su objetivo y transcurrido el tiempo recomendado para esperar su efecto, hubo que llevarlo al médico. Así es como, luego de haber sido internado tras un fuerte dolor abdominal, fue intervenido por una torsión intestinal. Transcurrió un mes en la clínica, al cuidado también de Olga, quien no le dejó un minuto y estuvo ahí, junto al artista admirado y respetado por ella, junto al hombre-hijo, amado-admirado. Junto al hombre sufriente en su expresión más pura de indefensión; vulnerado. Largos días sin ver a sus hijas le acongojaron, tuvo la alegría de ver a la menor gracias a su tenacidad que desacató la autoridad de los adultos y llegó hasta la clínica para verle. La mayor en tanto, de carácter más dócil y obediente, aceptó esperar pacientemente que regresara "la mamita con el papá”. Jamás sucedió. Olga regresó sola. Obtuvo parcialmente su 
objetivo, fue abrazada por su madre y, a la distancia, logró ver a su padre; esto perturbó a ambos, el artista se emocionó y la hija se "asustó" por el despliegue de "artefactos" circundantes a la cama de papá. Quedó en ambos un extraño sentido de satisfacción, pero ha de pervivir una disonante historia por la ausencia sempiterna de ese mundo maravilloso y seguro que constituía Roberto, a contar del instante que se entiende que "ya jamás volverá a verle".

La gravedad y sus convulsiones perturban el proceso de cerrar la herida operatoria; la cirugía no resultó eficaz y su desánimo es presenciado por Olga, quien permaneció acompañándolo por necesidad de "reproducir" lo que él necesitara expresar. Su capacidad de hablar disminuyó conjuntamente con la larga y tormentosa agonía. Por ello Olga era insustituible "ahí”. Había que tener celeridad en "transmitir" la sintomatología que el paciente explicaba.

Los sones de Roberto para concluir su propia sinfonía de dolor habrían de producirse muy pronto. Su director, la vida, ponía fin a su obra. El 12 de diciembre de 1958, murió Roberto Falabella Correa en la Clínica Alemana, acompañado de su esposa, quien estuvo con él hasta el último instante de su vida. El artista intentó una sonrisa, pidió por sus hijas y murió en brazos de su compañera. Está sepultado al interior del mausoleo que mandara construir su padre en el Cementerio General de la ciudad de Santiago de Chile. Allí permanecen sus restos junto a los de Olga, fallecida el año 2000, recibiendo tan sólo las visitas de sus hijas que no le olvidan.

\section{OLGA, XIMENA, FLORENCIA}

En verdad ellas tres son notas de una vida que tuvo la perfecta armonía de hacer tangible la belleza interior del artista, seres en donde la crudeza de la vida les invade. En medio de la ausencia, la alegría de sentir "aún les visita”. Para ello están las notas de su música en las que Roberto re-vive para tocar a los amados y acariciar desde lo etéreo y provocar sensitivos movimientos somáticos de estremecimientos con lo que hizo de sí, convirtiendo la adversidad puramente vital en belleza y delicada forma. Roberto en realidad "rompe" algo cuando permite sentirlo.

\section{OLGA DÍAZ BLANC, VIUDA DE FALABELLA}

Terminó su vida un 29 de junio del año 2000. Durmió su agonía y nombraba a Roberto, le cuidé cada minuto de su último tiempo, pasó un largo y triste período atendida en la salud pública, en donde los pacientes son una estadística, los trabajadores están sobreexigidos, los médicos con pocos recursos y tal pareciera que ser anciana, llegar a un servicio estatal de salud, no tener recursos económicos y estar casi en postración, fuese un atentado a la buena disposición de los funcionarios.

Cuidé a Olga. Le debo grandes lecciones aprendidas. Me presentó a Roberto, y yo he querido mantener la faceta más próxima del hombre que pasó tristezas tan humanas fuera del pentagrama y que las plasmó ahí. No se conocen con verdad las muchas vivencias que constituyen con toda seguridad la esencia de su obra.

Es sin duda un peculiar "guacho". Es exactamente el "guacho" que refleja en su obra. Es el que le dice a Olga que el texto correspondiente a sus Estudios Emocio- 
nales, repetido con fidelidad "ya nos vamos madre mía... para el año volveremos...", no es sino la reproducción exacta que reflejaba su propia sensación de miedo y abandono ante la partida de su madre, la tangible, la concreta que se le desaparecía por tan prolongados períodos, aumentando en él la sensación de abandono y de la que se prendaba haciendo fuerzas para resistir hasta el siguiente encuentro, esperando sentirse pleno de emoción y tocado como por el manto de protección de la divinidad encarnada en Femenino, cuando fuese que pudiera volver. La otra parte era una exacta "ironía", aludiendo a aquello "para el año...", haciendo ver con ello que se hacía muy distal una visita de otra. No desenmarcando el profundo y serio sentido de lo musical, la incorporación de lo folclórico en lo docto, la propuesta vanguardista de su creación. Procurando connotar desde su conocimiento que la promulgación de los credos y el acercamiento a lo divino es consecuencia del abandono del concepto "Dios" sobre la humanidad.

Había en su vida misterios cubiertos con tupido velo, no por acción propia, tal vez por algún tipo de estereotipado pudor, no obstante, la verdad se impone: Roberto fue un "guacho". Olga me lo mostró sufriente, el que no podía sonar su nariz ante el llanto provocado por la muerte de su padre, el que se conturbaba de emoción por serlo él mismo, el que dejaba su descanso por agasajar al amigo en dificultad, el que era capaz de beber y brindar con los amigos por una causa elevada y el que fue a un prostíbulo, el panfletario, el militante político, el que exigía igualdad de condiciones, el utópico, el cotidiano, el sereno, el artista que -permítanmelo- ha erizado mi piel al mostrar su alma cuando oí su música. He visto que su vida tiene una particular versión repetida en el alma frágil y dolorosa de una de sus hijas, a la cual ha "heredado" la forma de la tristeza en una constante repetición en las notas de su vida.

\section{ROBERTO, EL ARTISTA HOY}

Diciembre 12, año 2008 ¡Cincuenta años de su muerte! Tanto tiempo ha transcurrido y pareciera estar tan vivo, está presente en sus partituras, es motivo de estudios. Grandes directores de renombre internacional han elegido su obra para ser interpretada. Admirado por los estudiantes que apenas saben una pequeñita parte de la historia del hombre que "era" y que hasta hoy se mostraba escindido. Su integralidad de vida está reflejada en su obra.

Falabella compuso, de entre sus 61 obras, sólo cinco sinfónicas, las restantes son obras de cámara. También escribió poemas, de los cuales musicalizó algunos.

No nos permitamos dejar a Roberto en el polvo de sus partituras, que llegará emergente por sí mismo. No escindamos de nuestra sensibilidad la capacidad de expresar venciendo adversidades. No nos permitamos hacer de nuestra vida una excusa de no creer en la capacidad del arte por amor al arte que se produce desde el desgarro para solaz de otros.

Roberto se nos instala en nuestra conciencia como vencedor de toda adversidad, y como garante que la creatividad es factible desde el dolor o lo mismo, desde una alegría extrema.

¡Cincuenta años ha desde que muere y aún vive! 
Conocer de él es como si estuviese a punto de alcanzarnos con su mirada y prodigarnos su sonrisa o su crítica y su amistad y su dolor y su historia y su creación para hacernos "sentirle" y su mano conturbada por la parálisis para estrecharnos a su mundo tan vasto y bello. Es saber que, como lo escribió en uno de sus poemas, "nos abraza con la mirada".

Del carácter de su música, numerosos son los comentarios que no pueden eximirse del elogio por su dominio de la técnica, por la innovación del estilo, por lo precursor de las formas, por la incorporación del folclor a lo docto en la composición nacional, con representatividad de un contexto de denuncia social-político-cultural.

Soy neófita y muy ignorante de la música, sólo puedo referirme a lo que provocó en mí oír sus Estudios Emocionales para orquesta. ¡Me erizó la piel! Desconozco si la interpretación fue correctamente realizada, si bien dirigida o "convenció". En verdad sólo sé que fluyeron descontroladas mis emociones, aquello que oí era la presencia de ese maestro que desde su silla, postrado e inmóvil, tenía una mente brillante, veloz, absorbente y una exquisita sensibilidad. Era ¿un paria?, ¿un burgués?, ¿un talentoso tan sólo? ¡Tan al alcance y tan distante!

Aquello que él mismo ha dicho, que su música provoca "reacciones somáticas", lo he vivenciado. Había personas ahí que nada conocen de Roberto y la experiencia ha sido similar. Descubrimos, fuera de las formas del conocimiento musical, que posee un lenguaje que está tan bien expresado y hace sentido con cada célula de nuestro ser. La titánica fuerza de su desgarro en la vida transmite un mensaje poderoso. Roberto, el artista hoy, es un caminante a la posteridad junto a los iluminados de los dioses.

No puedo dejar de advertir que mi comentario es muy emocional. Consciente de ello, es mejor una observación propia de alguien verdaderamente conocedor del tema. Es por ello que no quiero dejar de transcribir el texto de quien fuera su maestro y amigo -privilegiado de serlo según propio comentario-, Gustavo Becerra:

"Cuando un hombre muere, deja generalmente una obra sobre la cual se fundamentan los juicios que sobre él se tengan como realizador. La obra de Falabella es abundante y variada. Dejan también los hombres a la posteridad herencias menos tangibles, pero a la vez más generosas e importantes. Nuestro artista nos ha dejado el ejemplo de la perseverancia en la nobleza de los propósitos por encima de dificultades increíbles. Nos ha dejado, además, un principio germinal: 'se puede hacer arte nacional sin caer en el nacionalismo'. Para demostrarlo están sus obras.

El más valioso ejemplo que nos ha dejado Roberto Falabella es el triunfo del dolor sobre la angustia. No podemos, por lo tanto, rendirle un homenaje que sólo revele nuestro dolor ante su inesperada y definitiva ausencia. A él únicamente se le podrá honrar siguiendo su ejemplo, triunfando por encima de las flaquezas en pro de la pureza de sus propósitos.

¡Anímenos su recuerdo para siempre!"8.

\footnotetext{
${ }^{8}$ Becerra 1958: 60.
} 


\section{BIBLIOGRAFÍA}

AsuAR, José Vicente

1968 “La Sinfonía de Roberto Falabella”, RMCh, XII/61 (septiembre-octubre), pp. 15-32.

Becerra, Gustavo

1958 "Necrología. Roberto Falabella Correa 1926-1958”, RMCh, XII/62 (noviembrediciembre), pp. 59-60.

1965 "Roberto Falabella, el hombre y su obra", RMCh XIX/91 (enero-marzo), pp. 28-36.

FALABELla, RoBERTo

1958a "Problemas estilísticos del joven compositor en América y en Chile", primera parte, $R M C h$, XII/57 (enero-febrero), pp. 42-49.

1958b "Problemas estilísticos del joven compositor en América y en Chile", segunda parte, $R M C h$, XII/58 (marzo-abril), pp. 77-93.

García, Fernando

1999 "Falabella Correa, Roberto". Diccionario de la Música Española e Hispanoamericana. Volumen 4. Emilio Casares Rodicio, editor y director general. Madrid: SGAE (Sociedad General de Autores y Editores), pp. 883-885.

GRANDELA, InÉs

1971 "Música chilena para piano de la generación joven (1925)", RMCh, XXV/113114 (enero-junio), pp. 35-54.

MERINO, Luis

1973 "Roberto Falabella Correa: el hombre, el artista y su compromiso", RMCh, XXVII/ 121-122 (enero-junio), pp. 45-112.

\section{Entrevistas}

La autora se entrevistó en numerosas ocasiones con las siguientes personas que conocieron de cerca a Roberto Falabella:

Gustavo Becerra, su maestro (contacto epistolar 2008-2009).

Isabel Correa, hija adoptada por la madre del compositor (ca. 2003).

Ariadna Colli, hija del músico Nino Colli, amigo de R. Falabella (ca. 1997-2002).

Olga Díaz Blanc, vda. de Falabella ( $c a$. 1994-2000).

María Gabriela del Carmen Falabella Correa, su hermana (ca. 2004).

Ximena y Florencia Falabella Díaz, sus hijas ( $c a$. 1994-2009).

Eduardo Moubarak, director de orquesta, amigo de R. Falabella (2008). 